\title{
Journal of Cancer Biology and Therapeutics KRAS and NRAS Mutations in Moroccan Patients with Colorectal Cancer
}

\author{
Dehbi $\mathrm{H}^{1,3^{*}}$, Ait boujmia OK${ }^{1}$, Benayad $\mathrm{S}^{2}$, El Idrissi $\mathrm{HH}^{1}$ and Karkouri $\mathbf{M}^{1,2}$ \\ ${ }^{1}$ Laboratory of Cellular and Molecular Pathology, Faculty of Medicine and Pharmacy of Casablanca, University \\ Hassan II, Casablanca, Morocco \\ ${ }^{2}$ Anathomo-Pathology Department, CHU Ibn Rochd, Casablanca, Morocco \\ ${ }^{3}$ Laboratory of medical Genetics, CHU Ibn Rochd, Casablanca, Morocco
}

*Correspondence: Hind Dehbi, Laboratory of Cellular and Molecular Pathology, Faculty of Medicine and Pharmacy of Casablanca, University Hassan II, Casablanca, Morocco, E-mail: dehbi@labgenmed.com

Received date: July 09, 2019; Accepted date: September 30, 2019; Published date: October 05, 2019

\begin{abstract}
Objective: Activating mutations in the RAS proto-oncogene (KRAS, HRAS and NRAS) play a crucial role in carcinogenesis and drug resistance in many cancers including, colorectal cancer. The aim of the present study was to evaluate the frequencies of KRAS and NRAS oncogenic mutations in Moroccan CRC patients.

Patients and methods: In the present study, formalin-fixed paraffin-embedded CRC specimens from 114 Moroccan CRC patients were analyzed. To detect mutations in codons 12, 13 and 61 of the KRAS and NRAS genes, the pyrosequencing technique was used.

Results: 114 colorectal cancer patients were included in this study, 64 were males and 50 were females, the primary tumor was the most frequent type (78.1\%) and the commonest histological type was ADK (77.2\%). KRAS mutation was found in 49 of all CRC patients and the most frequent KRAS mutations were 35G>T, 35G>A and 38G>A. On the other hand NRAS mutation was detected only in 6 patients. No statistically significant relationship between CRC patient's characteristics and RAS mutations was found.

Conclusion: Our results suggest that the KRAS mutation is more frequent among Moroccan patients with CRC, which is in agreement with the most previous studies. Further studies, with a larger number of CRC patients, are needed to confirm our findings.
\end{abstract}

Keywords: KRAS, NRAS, Colorectal cancer, Morocco

\section{Introduction}

Colorectal Cancer (CRC) is defined by the malignant proliferation of cells lining the walls of the colon or rectum. CRC is the third most common cancer in the world after lung and breast cancer. Each year, over one million people are diagnosed with colorectal cancer and over half a million die from it [1-5]. The incidence of this cancer varies from country to country due to differences in diet, lifestyle, and genetic background between populations [6]. This cancer most often occurs sporadically and the hereditary form represents about 5\% [7].The adenocarcinoma is the most common histological type [8].The risk factors for CRC including, cholecystectomy, inflammatory bowel disease, irradiation, obesity, smoking, high alcohol consumption, diet rich on red or processed meats [9].

Activating mutations in the RAS proto-oncogene family (KRAS, HRAS and NRAS) played an important role in carcinogenesis, progression and drug resistance in many cancers by altering biological functions such as, apoptosis, cell proliferation and differentiation [10]. The frequencies of these mutations vary according 
to ethnic groups and geographic factors.

In CRC, the KRAS gene is frequently mutated mainly in the codons $12,13,59,61$, and 146 . Mutations in this gene represent about 27 to $56 \%$ of CRC cases and have been reported to be a negative prognostic marker that induces resistance against to treatment with anti-EGFR antibodies cetuximab and panitumumab [10-13].The NRAS gene is rarely mutated in this cancer in about 1 to $7 \%$ of cases [10-12].

The aim of the present study was to estimate the frequencies of KRAS and NRAS mutations using pyrosequencing in a sample of a Moroccan population.

\section{Patients and Methods}

114 formalin-fixed paraffin-embedded CRC specimens were analyzed in the present study. Clinical and demographic factors, such as: age, sex, Tumor type, Histological type, etc were collected from patient records. The study was approved by the local ethics committee of the Hassan II University and written informed consent was obtained from each patient Table 1.

Table 1: Clinical Characteristics of the 114 colorectal cancer patients.

\begin{tabular}{|c|c|}
\hline & Cases $(\mathrm{N}=114)$ \\
\hline \multicolumn{2}{|l|}{$\operatorname{Sex} N(\%)$} \\
\hline Females & $50(43.9 \%)$ \\
\hline Males & $64(56.1 \%)$ \\
\hline M:F ratio & 1.28 \\
\hline Age years (Mean) & 55.41 \\
\hline Range & $19-84$ \\
\hline$\leq 50$ & $44(38.6 \%)$ \\
\hline $51-64$ & $50(43.9 \%)$ \\
\hline$\geq 65$ & $20(17.5 \%)$ \\
\hline \multicolumn{2}{|l|}{ Tumor type } \\
\hline Primary & $89(78.1 \%)$ \\
\hline Metastasis & $23(20.2 \%)$ \\
\hline local recurrence & $2(1.8 \%)$ \\
\hline \multicolumn{2}{|l|}{ Tumor percentage } \\
\hline$<50$ & $70(61.4 \%)$ \\
\hline$\geq 50$ & $44(38.6 \%)$ \\
\hline \multicolumn{2}{|l|}{ Histological type } \\
\hline ADK & $88(77.2 \%)$ \\
\hline Others & $26(22.8 \%)$ \\
\hline
\end{tabular}

\section{Genomic DNA extraction}

The genomic DNA was purified from formalin-fixed paraffin-embedded tissues samples using the QIAamp DNA FFPE Tissue Kit (Qiagen, Valencia, CA, USA), extracted DNA samples were quantified on the NanoDrop. Carry out the DNA extraction according to the instructions in the kit handbooks. For detecting KRAS and NRAS samples were analyzed by quantitative PCR and Pyrosequencing.

\section{PCR amplification and Pyrosequencing}

PCR was used for amplifications of a region containing codon 12, codon 13, and codon 61.PCR assay was performed in a reaction volume of $20 \mu \mathrm{L}$ using $12.5 \mu \mathrm{L}$ PyroMark PCR Master Mix, 2,5 $\mu \mathrm{L}$ CoralLoad Concentrate, 10x, $1 \mu \mathrm{L}$ PCR Primer and $4 \mu \mathrm{L}$ Water (H2O, supplied). The PCR conditions were as follows: Initial denaturation at $95^{\circ} \mathrm{C}$ for $15 \mathrm{~min}$, followed by 40 cycles of $95^{\circ} \mathrm{C}$ for 20 sec, $53^{\circ} \mathrm{C}$ for $30 \mathrm{~s}$ and extension at $72^{\circ} \mathrm{C}$ for $20 \mathrm{sec}$ and then final extension at $72^{\circ} \mathrm{C}$ for $5 \mathrm{~min}$ ). Unmethylated control DNA was included in the product as a positive control for PCR and sequencing reactions. In addition, a negative control (without template DNA) was included. After PCR, the amplicons are immobilized on Streptavidin Sepharose High Performance beads. Single-stranded DNA is prepared and the corresponding sequencing primers anneal to the DNA. The KRAS, NRAS (codons $12,13,61$ ) oncogenes mutations were detected by the pyrosequencing technique using Pyro kit (Qiagen).

\section{Statistical analysis}

Statistical analyses were performed using the SPSS software package version 17.0 (SPSS Inc., Chicago, IL, USA). For all the analyses, $P$ values $<0.05$ were considered statistically significant.

\section{Results}

114 colorectal cancer patients were included in the present study, 64 (56.1\%) were males and 50 (43.9\%) were females; with a sex ratio of 1.28 . The mean age of our patients was 55.41 years; the majority of our patients were aged less than 50 years (61.4\%). For the tumor type, the primary tumor was the most dominant type with a frequency of $78.1 \%$. The most frequently histological type ADK, was seen in $77.2 \%$ of all cases. The tumor percentage was less than 50 at diagnosis in $61.4 \%$ of patients. The characteristics of the 114 CRC patients are summarized in table 1.

For the RAS mutations, a KRAS mutation was found in 49 of CRC patients (43\%). The most frequent mutations 
were 35G>T (36.7\%), 35G>A (14.3\%) and 38G>A (14.3\%). KRAS exon 2 mutations were detected in 46 patients (93.9\%) and mutations outside KRAS exon 2 were found in $6 \%$ of our patients. On the other hand NRAS mutation was detected in 6 patients (5.3\%) and the most common mutations were $181 \mathrm{C}>\mathrm{A}(2.6 \%)$ and $182 \mathrm{~A}>\mathrm{G}$ (1.8\%) (Table 2). We did not find any significant correlation between patients characteristics age, sex, Tumor type, etc and RAS mutations (Table 3).

Table 2: KRAS and NRAS mutations among the 114 colorectal cancer patients.

\begin{tabular}{|c|c|c|}
\hline & & $\begin{array}{l}\text { Cases } \\
(\mathrm{N}=114)\end{array}$ \\
\hline \multicolumn{3}{|l|}{ KRAS N (\%) } \\
\hline & Wild type & $58(50.9)$ \\
\hline & Mutated & $49(43)$ \\
\hline \multicolumn{3}{|l|}{ NRAS N (\%) } \\
\hline & Wild type & $101(88.6)$ \\
\hline & Mutated & $6(5.3)$ \\
\hline \multicolumn{3}{|c|}{ KRAS( $\%$ of mutated cases) } \\
\hline exon 2 & $38 \mathrm{G}>\mathrm{A}$ & $7(14.3 \%)$ \\
\hline Codons 12, 13 & $\begin{array}{l}35 G>T \\
35 G>A \\
34 G>T \\
37 G>T \\
34 G>A \\
35 G>C \\
34 G>C\end{array}$ & $\begin{array}{l}18(36.7 \%) \\
7(14.3 \%) \\
4(8.2 \%) \\
1(2.0 \%) \\
4(8.2 \%) \\
3(6.1 \%) \\
1(2.0 \%)\end{array}$ \\
\hline exon 3 & $182 \mathrm{~A}>\mathrm{T}$ & $1(2.0 \%)$ \\
\hline Codons 61 & $\begin{array}{l}183 A>G \\
175 G>A\end{array}$ & $\begin{array}{l}1(2.0 \%) \\
1(2.0 \%)\end{array}$ \\
\hline exon 2 & $436 \mathrm{G}>\mathrm{A}$ & $1(2.0 \%)$ \\
\hline \multicolumn{3}{|c|}{ NRAS(\% of mutated cases) } \\
\hline exon 3 & $181 \mathrm{C}>\mathrm{A}$ & $3(50 \%)$ \\
\hline Codons 61 & $\begin{array}{l}182 A>G \\
181 A>G\end{array}$ & $\begin{array}{l}2(33.3 \%) \\
1(16.7 \%)\end{array}$ \\
\hline
\end{tabular}

\section{Discussion}

In our study CRC was more common among males, a similar result was obtained by other authors [1418]; this increased susceptibility could be explained by genetic and physiological differences between men and women, men are more likely to use alcohol and tobacco and more likely to consume red meat.

The mean age of our patients was 55.41 and the most frequent age range was 51 to 64 years, these results were in agreement with Greater Casablanca cancer registry report 2012 and with Jouini et al findings in the
Tunisian population $[19,20]$. The most tissue specimens were from primary tumors, a similar result was reported by Jouini, et al. and Lee et al. [20,21].The majority of our patients were diagnosed with adenocarcinoma, this result was similar to that reported by Lee et al and Rindi et al. $[8,21]$.

Table 3: Association of clinical Characteristics and RAS mutations in colorectal cancer patients.

\begin{tabular}{|c|c|c|c|c|c|c|}
\hline \multicolumn{3}{|c|}{ NRAS } & \multicolumn{4}{|c|}{ KRAS } \\
\hline & $\mathbf{N}$ & $\mathbf{P}$ & $P$ value & $\mathbf{N}$ & $\mathbf{P}$ & $P$ value \\
\hline \multicolumn{7}{|l|}{ Sex $N$} \\
\hline Females & 44 & 3 & 0.75 & 25 & 22 & 0.85 \\
\hline Males & 57 & 3 & & 33 & 27 & \\
\hline \multicolumn{7}{|l|}{ Age years } \\
\hline$\leq 50$ & 39 & 2 & 0.63 & 24 & 17 & 0.6 \\
\hline $51-64$ & 44 & 2 & & 25 & 21 & \\
\hline$\geq 50$ & 18 & 2 & & 9 & 11 & \\
\hline \multicolumn{7}{|c|}{ Tumor type } \\
\hline Primary & 80 & 5 & 0.93 & 43 & 42 & 0.29 \\
\hline Metastasis & 19 & 1 & & 14 & 6 & \\
\hline $\begin{array}{l}\text { Local } \\
\text { recurrence }\end{array}$ & 2 & 0 & & 1 & 1 & \\
\hline \multicolumn{7}{|c|}{ Tumor percentage } \\
\hline$<50$ & 65 & 3 & 0.47 & 37 & 31 & 0.95 \\
\hline$\geq 50$ & 36 & 3 & & 21 & 18 & \\
\hline \multicolumn{7}{|c|}{ Histological type } \\
\hline ADK & 79 & 36 & 0.24 & 48 & 36 & 0.24 \\
\hline Others & 22 & 13 & & 10 & 13 & \\
\hline
\end{tabular}

We did not find any correlation between the clinical parameters such as age, sex, stage of disease with RAS mutations, our results agreed with the observations of Most of the previous studies [21-25].

The current study results showed that the KRAS gene mutation was seen in $43 \%$ of all CRC patients. Similarly, it was reported in the literature that the frequency of this activating mutation accounts for approximately $24 \%-43 \%$ of all CRC patients $[20,22,26,27]$.

NRAS mutations were observed in 5.3\% of the 114 patients, which agreed with the reported frequencies (3$20 \%)$ in the literature [10-12,20,28-30]. The KRAS exon 2 mutations were the most common mutations in our work, among these mutations, the most frequent were $35 \mathrm{G}>\mathrm{T}(36.7 \%), 35 \mathrm{G}>\mathrm{A}(14.3 \%)$ and 38G>A (14.3\%) this result was comparable with those obtained in other studies $[20,31,32]$. Similar to our results, a low incidence 
of outside mutations KRAS exon 2 has been detected in CRC cancer with frequencies between $3 \%$ and $31 \%[20,28$ $30,33,34]$.

For the KRAS mutation, it has been reported that the exon2 mutations influence the anti-EGFR therapy efficacy; patients with KRAS exon 2 wild type genotype are sensitive to anti-EGFR therapy and mutations outside of KRAS can cause resistance to anti EGFR monoclonal antibodies, for these reasons, the analysis of KRAS mutations should be included in routine clinical practice to improve the clinical response and survival of CRC patients [35-37].

\section{Conclusion}

The present study suggests that the KRAS mutation is more frequent while the NRAS mutation is rare among Moroccan patients with CRC, which is in agreement with the most previous studies among different ethnic groups. Further studies with large population size are needed to confirm these results.

\section{References}

1. World Health Organization Cancer incidence in Five Continents. Lyon: The World Health Organization and the International Agency for Research on Cancer; 2002.

2. World Cancer Research Fund and American Institute for Cancer Research Food, Nutrition, Physical Activity, and the Prevention of Cancer: A Global Perspective. Washington, DC: American Institute for Cancer Research; 2007.

3. Boyle P, Ferlay J. Mortality and survival in breast and colorectal cancer. Nat Clin Pract Oncol. 2005;2(9):424425. Doi: https://dx.doi.org/10.1038/ncponc0288

4. Parkin DM, Bray F, Ferlay J, et al. Global cancer statistics, 2002. CA Cancer J Clin. 2005;55(2):74-108. Doi: https://dx.doi.org/10.3322/canjclin.55.2.74

5. Bray F, Ferlay J, Soerjomataram I, et al. Global cancer statistics 2018: GLOBOCAN estimates of incidence and mortality worldwide for 36 cancers in 185 countries. CA Cancer J Clin. 2018;68(6):394-424. Doi: https://dx.doi.org/10.3322/caac.21492

6. Boyle $\mathrm{P}$, Langman JS. ABC of colorectal cancer: Epidemiology. BMJ. 2000;321(7264):805-808. Doi: https://dx.doi.org/10.1136/bmj.321.7264.805

7. Jackson-Thompson J, Ahmed F, German RR, et al. Descriptive epidemiology of colorectal cancer in the United States, 1998-2001. Cancer. 2006;107(5
Suppl):1103-1111. Doi: https://dx.doi.org/10.1002/ cncr.22007

8. Rindi G, Arnold R, Bosman F, et al. Nomenclature and classification of neuroendocrine neoplasms of the digestive system. In: Bosman F, Carneiro F, Hruban $\mathrm{RH}$, et al. ed. WHO classification of tumors of the digestive system. Lyon: IARC; 2010.

9. Janout V, Kollárová H. Epidemiology of colorectal cancer. Biomed Pap Med Fac Univ Palacky Olomouc Czech Repub. 2001;145(1):5-10. https://www.ncbi.nIm. nih.gov/pubmed/12415635

10. Kodaz H, Osman K, Muhammet BH, et al. Frequency of ras mutations (Kras, nras, hras) in human solid cancer. EJMO. 2017;1(1):1-7. Doi: https://dx.doi. org/10.14744/ejmo.2017.22931

11. Bos JL. Ras oncogenes in human cancer: a review. Cancer Res. 1989;49(17):4682-4689. https://www.ncbi. nlm.nih.gov/pubmed/2547513

12. Fernández-Medarde A, Santos E. Ras in cancer and developmental diseases. Genes Cancer. 2011;2(3):344-358. Doi: https://dx.doi. org/10.1177/1947601911411084

13. Bardelli A, Siena S. Molecular mechanisms of resistance to cetuximab and panitumumab in colorectal cancer. J Clin Oncol. 2010;28(7):1254-1261. Doi: https://dx.doi.org/10.1200/JCO.2009.24.6116

14. CRUK/NCIN. Excess cancer burden in men. London: Cancer Research UK, NCIN, Leeds Met University, Men's Health Forum; 2013.

15. Edgren G, Liang L, Adami HO, et al. Enigmatic sex disparities in cancer incidence. Eur J Epidemiol. 2012;27(3):187-196. Doi: https://dx.doi.org/10.1007/ s10654-011-9647-5

16. Cook MB, McGlynn KA, Devesa SS, et al. Sex disparities in cancer mortality and survival. Cancer Epidemiol Biomarkers Prev. 2011;20(8):1629-1637. Doi: https:// dx.doi.org/10.1158/1055-9965.EPI-11-0246

17. Bates B, Cox L, Nicholson S, et al. National diet and nutrition survey: results from years 5 and 6 (combined) of the rolling programme (2012/20132013/2014) London: Public Health England; 2016.

18. Schütze $M$, Boeing $H$, Pischon $T$, et al. Alcohol attributable burden of incidence of cancer in eight European countries based on results from prospective cohort study. BMJ. 2011;342:d1584. Doi: https://dx.doi.org/10.1136/bmj.d1584

19. Cancer register of Casablanca 2008-2012. Available at:http://www.contrelecancer.ma/site_media/ 
uploaded_fil es/RCRGC.pdf.

20. Jouini R, Ferchichi M, BenBrahim E, et al. KRAS and NRAS pyrosequencing screening in Tunisian colorectal cancer patients in 2015. Heliyon. 2019;5(3):e01330. Doi: $\quad$ https://dx.doi.org/10.1016/j.heliyon.2019. e01330

21. Lee $\mathrm{SH}$, Chung $A M$, Lee $A$, et al. Kras mutation test in korean patients with colorectal carcinomas: a methodological comparison between sanger sequencing and a real-time pcr-based assay. J Pathol Transl Med. 2017;51(1):24-31. Doi: https://dx.doi. org/10.4132/jptm.2016.10.03

22. Imyanitov EN, Mitiushkina NV, Kuligina ES, et al. 586PSequencing of KRAS and NRAS in 1501 colorectal carcinomas reveals significant share of mutations, which are not, included in common diagnostic kits. Ann Oncol. 2018;29(suppl_8). Doi: https://dx.doi. org/10.1093/annonc/mdy281.132

23. Al-Shamsi HO, Jones J, Fahmawi $Y$, et al. Molecular spectrum of KRAS, NRAS, BRAF, PIK3CA, TP53, and APC somatic gene mutations in Arab patients with colorectal cancer: determination of frequency and distribution pattern. I Gastrointest Oncol. 2016;7(6):882-902. Doi: https://dx.doi.org/10.21037/ jgo.2016.11.02

24. Er TK, Chen CC, Bujanda L, et al. Current approaches for predicting a lack of response to anti-EGFR therapy in KRAS wild-type patients. Biomed Res Int. 2014;2014:591867. Doi: https://dx.doi. org/10.1155/2014/591867

25. Bagadi SB, Sanghvi M, Nair SB, et al. Combined mutational analysis of KRAS, NRAS and BRAF genes in Indian patients with colorectal carcinoma. Int J Biol Markers. 2012;27(1):27-33. Doi: https://dx.doi. org/10.5301/JBM.2012.9108

26. Samowitz WS, Curtin K, Schaffer D, et al. Relationship of Ki-ras mutations in colon cancers to tumor location, stage, and survival: a population-based study. Cancer Epidemiol Biomarkers Prev. 2000;9(11):1193-1197. Doi: https://www.ncbi.nlm.nih.gov/pubmed/11097226

27. Andreyev HJ, Norman AR, Cunningham D, et al. Kirsten ras mutations in patients with colorectal cancer: the "RASCAL II" study. Br J Cancer. 2001;85(5):692-696. Doi: https://dx.doi.org/10.1054/bjoc.2001.1964

28. Bruera G, Pepe F, Malapelle U, et al. Differential clinical outcome of metastatic colorectal cancer (Mcrc) patients (Pts) treated with first line Flr-B/FOx adding bevacizumab (Bev) to triplet chemotherapy according to KRAS, NRAS and BRAF genotype detected by massive parallel sequencing. JCO. 2017;35(15_suppl):e15041-e15041. Doi: https:// dx.doi.org/10.1200/JCO.2017.35.15_suppl.e15041

29. Foltran L, De Maglio G, Pella N, et al. Prognostic role of KRAS, NRAS, BRAF and PIK3CA mutations in advanced colorectal cancer. Future Oncol. 2015;11(4):629-640. Doi: https://dx.doi.org/10.2217/fon.14.279

30. Guo $F$, Gong $H$, Zhao $H$, et al. Mutation status and prognostic values of KRAS, NRAS, BRAF and PIK3CA in 353 Chinese colorectal cancer patients. Sci Rep. 2018;8(1):6076. Doi: https://dx.doi.org/10.1038/ s41598-018-24306-1

31. Negru S, Papadopoulou E, Apessos A, et al. KRAS, NRAS and BRAF mutations in Greek and Romanian patients with colorectal cancer: a cohort study. BMJ Open. 2014;4(5):e004652. Doi: https://dx.doi. org/10.1136/bmjopen-2013-004652

32. Ouerhani S, Bougatef $K$, Soltani I, et al. The prevalence and prognostic significance of KRAS mutation in bladder cancer, chronic myeloid leukemia and colorectal cancer. Mol Biol Rep. 2013;40(6):4109-4114. Doi: https://dx.doi.org/10.1007/s11033-013-2512-8

33. Schirripa M, Cremolini C, Loupakis F, et al. Role of NRAS mutations as prognostic and predictive markers in metastatic colorectal cancer. Int J Cancer. 2015;136(1):83-90. Doi: https://dx.doi.org/10.1002/ ijc.28955

34. Bruera G, Pepe F, Malapelle U, et al. KRAS, NRAS and BRAF mutations detected by next generation sequencing, and differential clinical outcome in metastatic colorectal cancer (Mcrc) patients treated with first line FIr-B/FOx adding bevacizumab (Bev) to triplet chemotherapy. Oncotarget. 2018;9(41):2627926290. Doi: https://dx.doi.org/10.18632/ oncotarget. 25180

35. Allegra CJ, Jessup JM, Somerfield MR, et al. American Society of Clinical Oncology provisional clinical opinion: testing for KRAS gene mutations in patients with metastatic colorectal carcinoma to predict response to anti-epidermal growth factor receptor monoclonal antibody therapy. J Clin Oncol. 2009;27(12):2091-2096. Doi: https://dx.doi.org/10.1200/JCO.2009.21.9170

36. Hecht JR, Douillard JY, Schwartzberg L, et al. Extended RAS analysis for anti-epidermal growth factor therapy in patients with metastatic colorectal cancer. Cancer Treat Rev. 2015;41(8):653-659. Doi: https://dx.doi. org/10.1016/j.ctrv.2015.05.008

37. Sforza V, Martinelli E, Ciardiello F, et al. Mechanisms of resistance to anti-epidermal growth factor receptor 
inhibitors in metastatic colorectal cancer. World J

Gastroenterol. 2016;22(28):6345. Doi: https://dx.doi.

org/10.3748/wjg.v22.i28.6345

Copyright: ( $)$ Dehbi et al. This is an Open Access article distributed under the terms of the Creative Commons Attribution License, which permits unrestricted use, distribution, and reproduction in any medium, provided the original work is properly cited. 